Short-and long-term outcomes of video-assisted thoracoscopic lobectomy in elderly patients with non-small-cell lung cancer

\title{
Yang Yang
}

Yanan University Affiliated Hospital

\section{Kai Wang}

Yanan University Affiliated Hospital

\section{Qingquan Ren}

Yanan University Affiliated Hospital

\section{Ruibin Xu}

Yanan University Affiliated Hospital

Jianfeng Guo ( $\nabla$ thoracliu@163.com )

Yanan University Affiliated Hospital

\section{Research}

Keywords: lobectomy, minimally invasive surgery, non-small cell lung cancer, video-assisted thoracoscopic surgery, prgnosis

Posted Date: August 3rd, 2020

DOl: https://doi.org/10.21203/rs.3.rs-50006/v1

License: (c) (1) This work is licensed under a Creative Commons Attribution 4.0 International License. Read Full License 


\section{Abstract}

Objective This study aimed to explore the short-and long-term outcomes of video-assisted thoracoscopic (VATS) lobectomy in older patients with non-small-cell lung cancer (NSCLC).

Methods A total of 218 NSCLC patient data between January 2014 and January 2019, which included pathological, clinical, and follow-up surveys on VATS lobectomy, were retrospectively analyzed. Of the 218-patient data analyzed, a total of 77 patients were 70 years of age and older (elderly group), while a total of 141 patients were below 70 years of age (nonelderly group).

Results Concerning general preoperative data, the simplified comorbidity score (SCS) and the American Society of Anesthesiologists (ASA) scores were higher in the elderly patient group as compared to the nonelderly patient group. Also, elderly patients had poor pulmonary function performance as compared to their counterparts. There were, however, no significant statistical differences found with surgical data between the two groups concerning intraoperative blood loss, operation duration, and conversion to thoracotomy. None of the patients in either of the groups died within thirty days of the operation. Additionally, there were no significant statistical differences in the five-year overall survival rate and the five-year disease-free survival rate between both groups.

Conclusion NSCLC treatment with VATS lobectomy is safe and feasible in elderly patients, and it can provide excellent long-term outcomes. However, it is necessary to strengthen perioperative management and promote early postoperative recovery to reduce complications.

\section{Introduction}

Lung cancer is one of the leading causes of cancer-related deaths worldwide and poses a severe threat to human health [1-2]. The global incidence of lung cancer has increased significantly in the past 50 years [3]. Both in developed and developing countries, the prevalence of lung cancer is the highest among all malignant tumors and is related to smoking, occupational carcinogens, air pollution, and ionizing radiation[3]. According to histopathology, lung cancer is classified into non-small-cell lung cancer (NSCLC) and small-cell lung cancer (SCLC) [4]. Among them, NSCLC is the most prevalent, which constitutes about $85 \%$ of the total cases [4]. Patients diagnosed with NSCLC in developed countries have a median age of sixty-nine and sixty-seven years in both men and women, respectively [5-7]. With the average age of the Chinese population on the rise, the number of elderly NSCLC patients in China is showing an increasing trend [5-7]. At present, the principal methods for treating NSCLC are surgery, radiotherapy, and chemotherapy [8]. For patients the first and second clinical-stage (cl to II) NSCLC, the preferred treatment method is surgery. Lobectomy is the standard surgery for cl to II NCSLC [8].

Elderly patients have considerable concerns regarding open lobectomy as it is highly invasive and has numerous complications [9]. Elderly NSCLC patients treated with thoracic lobectomy have a postoperative mortality rate of 0 to $4.8 \%$ and a postoperative complication rate of $20-54 \%[9,10]$. Since the first videoassisted thoracoscopic (VATS) lobectomy was performed in 1992 [11], the continuous development of 
minimally invasive surgical techniques and instruments, accumulation of surgical experience, and continuous reports of good long-term survival in surgical patients [12-27] has prompted the NCCN guidelines to recommend VATS lobectomy as a surgical method for treatment of resectable NSCLC [28]. However, there are few studies on VATS lobectomy in elderly NSCLC patients, and majority of them only report short-term outcomes [29-37]. This study aimed to compare the efficacy of VATS lobectomy in elderly versus non-elderly NSCLC patients in order to explore the short-and long-term outcomes of VATS lobectomy in elderly NSCLC patients.

\section{Patients And Methods}

This study complied with the Declaration of Helsinki. This retrospective research was approved by the ethics review board of Yanan University Affiliated Hospital. The need for informed consent from all patients was waived because of retrospective study, not prospective trial.

We carried out a retrospective analysis of VATS lobectomy patients in our institution between the period of January 2014 and January 2019. The inclusion criteria were: (1) patients in whom postoperative pathology confirmed NSCLC; (2) patients who had preoperative clinical stage I to II NSCLC; (3) patients who had not received neoadjuvant therapy, interventional therapy, and other tumor-related treatments before surgery; (4) patients whose data were complete. The exclusion criteria were, however: (1) patients with metastatic cancer, (2) patients with other MTs or with a history of MTs. Of the 218-patient data analyzed, a total of 77 patients were 70 years of age and older (elderly group), while a total of 141 patients were below 70 years of age (nonelderly group).

The patients underwent double-lumen tracheal intubation and were positioned in the lateral decubitus position. They underwent intraoperative unilateral ventilation of the healthy lung. A 2-cm incision was made at the 7th intercostal space in the midaxillary line as a thoracoscopic observation hole. Furthermore, after considering the position of the tumor, a 2-cm incision was made as an operation hole at the sixth, seventh, and eighth intercostal space in the posterior axillary line, and a 3-5-cm operation hole was made at the fourth or fifth intercostal space in the anterior axillary line. Under thoracoscopy, lobectomy and mediastinal lymph node dissection were performed. During the operation, pulmonary veins and bronchi were divided with a disposable linear cutter stapler. Pulmonary artery branches were double ligated with a common silk ligature and divided with an ultrasonic dissector followed by ligation either with Hem-o-Lok clips or with a disposable linear cutter stapler. Excised lymph nodes consisted of the intra-pulmonary, pulmonary hilar, and mediastinal lymph nodes, with the latter comprising mediastinal lymph nodes at stations $4 \mathrm{~L}$ and 5-9 in the left mediastinum and at stations $2 \mathrm{R}, 4 \mathrm{R}$, and 7-9 in the right mediastinum [38]. Perioperative management was carried out using the Enhanced Recovery After Surgery (ERAS) principles [39-41].

The Clavien-Dindo classification system was used to classify postoperative complications severity [4246]. Cause of death, overall survival, local recurrence, disease-free survival, and distant metastasis were recorded during follow-up. Overall survival, disease-free survival, local recurrence, distant metastasis, and 
cause of death of the patients were recorded in the follow-up, which was conducted through outpatient visits, telephone interviews, or home visits, or was entrusted to the local hospital physicians. The last follow-up was performed on June 1, 2020. Local recurrence was defined as recurrence of the primary lesion or recurrence in the corresponding drainage area, including recurrence in the pulmonary hilar and mediastinal lymph nodes as well as bronchial stump recurrence, while recurrence at other sites was defined as distant metastasis.

\section{Statistics}

All the statistical analyses were performed using SPSS, Version 14.0 (SPSS Inc., Chicago, IL, USA). Normally distributed variables were analyzed by Student $t$ tests and presented as means and standard deviations. Non-normally distributed variables were analyzed by Mann-Whitney Utest and presented as medians and ranges. Differences between semiquantitative results were analyzed by Mann-Whitney $U$ tests. Differences between qualitative results were analyzed by chi-square or Fisher exact tests, as appropriate. Survival rates were analyzed by the Kaplan-Meier method, and differences between the two groups were analyzed by log-rank test. Multivariate Cox regression analysis was performed to identify factors predictive of poor disease-free survival and overall survival by using both forward and backward stepwise selection. Explanatory variables with univariate $P$ values $\leq 0.100$ were included in the multivariate analysis. The results are reported as hazard ratios with $95 \%$ confidence intervals. $P<0.05$ was considered to be statistically significant.

\section{Results}

Concerning general preoperative data, the simplified comorbidity score (SCS) and the ASA scores were higher in the elderly group as compared to the nonelderly group. Also, elderly patients had poor pulmonary function performance as compared to their counterparts. There was no statistically significant difference in other general preoperative data (Table 1).

Table 1 Comparison of baseline characteristics of the two groups 


\begin{tabular}{|c|c|c|c|}
\hline Characteristics & $\begin{array}{c}\text { Elderly } \\
(n=77)\end{array}$ & Nonelderly $(n=141)$ & $P$ value \\
\hline Age (y) & $73(70-77)$ & $61(45-69)$ & 0.000 \\
\hline Gender (Male: Female) & 51: 26 & $97: 44$ & 0.699 \\
\hline SCS & & & 0.008 \\
\hline$\geq 9$ & 21 & 18 & \\
\hline Pulmonary function & 56 & 123 & \\
\hline FEV1 (L) & $2.3(1.8-2.7)$ & $2.6(1.9-2.9)$ & 0.044 \\
\hline MVV (\%) & $74(69-97)$ & $80(71-98)$ & 0.040 \\
\hline Clinical TNM stage & & & 0.949 \\
\hline IA & 2 & 5 & \\
\hline IB & 23 & 41 & \\
\hline IIA & 36 & 67 & \\
\hline IIB & 16 & 29 & \\
\hline ASA score & & & 0.000 \\
\hline & 45 & 118 & \\
\hline II & 26 & 19 & \\
\hline III & 6 & 4 & \\
\hline Tumor location & & & \\
\hline Left upper lobe & 12 & 21 & 0.842 \\
\hline Left lower lobe & 14 & 25 & 0.934 \\
\hline Right lower lobe & 19 & 24 & 0.175 \\
\hline Right upper lobe & 23 & 51 & 0.348 \\
\hline Right middle lobe & 9 & 20 & 0.604 \\
\hline
\end{tabular}

SCS: Simplified Comorbidity Score

ASA: American Society of Anesthesiologists

FEV1: Forced Expiratory Volume in the first second

MVV: maximal voluntary ventilation

There were, however, no significant statistical differences found with surgical data between the two groups concerning intraoperative blood loss, operation duration, and significant postoperative complications within thirty days (Table 2), nor pathological outcomes (Table 3).

Table 2 Comparison of surgical outcomes of the two groups 


\begin{tabular}{lccc}
\hline \multicolumn{1}{c}{ Outcomes } & $\begin{array}{c}\text { Elderly } \\
(n=77)\end{array}$ & Nonelderly $(n=141)$ & $P$ value \\
\hline Conversion to thoracotomy & 2 & 3 & 1.000 \\
& $190(160-290)$ & $180(140-270)$ & 0.279 \\
Blood loss (ml) & $180(150-220)$ & $170(140-230)$ & 0.354 \\
Surgical duration (min) & $5(4-9)$ & $5(3-8)$ & 0.589 \\
Tube duration (d) & $10(7-20)$ & $9(6-17)$ & 0.397 \\
postoperative hospital stay (days) & 10 & 12 & 0.294 \\
Patients with postoperative 30-day complications & & 5 & \\
Pneumonia & 4 & 2 & \\
$\quad$ Atelectasis & 2 & 2 & \\
$\quad$ Prolonged air leak (more than 7 days) & 1 & 1 & \\
$\quad$ Respiratory failure & 1 & 0 & \\
$\quad$ Acute heart failure & 1 & 2 & \\
$\quad$ Arrhythmia & 1 & 2 & \\
Patients with major complications & 1 & 0 & \\
postoperative 30-day mortality & 0 & & \\
\hline
\end{tabular}

Table 3 Comparison of pathological outcomes of the two groups

\begin{tabular}{lccc}
\hline \multicolumn{1}{c}{ Outcomes } & $\begin{array}{c}\text { Elderly } \\
(n=77)\end{array}$ & Nonelderly $(n=141)$ & $P$ value \\
\hline Histological type & 53 & 97 & 0.997 \\
Adenocarcinoma & 24 & 44 & \\
Squamous cell carcinoma & $12(9-21)$ & $13(10-25)$ & 0.418 \\
Harvested lymph nodes & & & 0.805 \\
Pathological stage & 1 & 3 & \\
IA & 19 & 35 & \\
IB & 24 & 44 & \\
IIA & 21 & 39 & \\
IIB & 12 & 20 & \\
IIIA & & & \\
Residual tumor & 77 & 141 & \\
R0 & 0 & 0 & \\
R1 & 0 & 0 & \\
R2 & & & \\
\hline
\end{tabular}

In this study, a total of 22 complications occurred 30 days after surgery, and no patient had more than two complications (Table 2). There were ten and twelve cases of complications in two groups, elderly group and non-elderly group, respectively (Table 2 ). The complications included pulmonary infection, atelectasis, air leak, and respiratory failure in order of decreasing incidence (Table 2). In terms of complications severity, two patients in both groups had a major 30-day postoperative complication (Table 2). None of the patients in either of the groups died within 30 days of the operation (Table 2).

There were two and three cases of conversion to thoracotomy in the elderly group and non-elderly group, respectively (Table 2). Among the two cases in the elderly group, one presented with calcified lymph nodes, which were adherent to the pulmonary vessels and difficult to separate; the other one presented 
with pulmonary vessel injury. Among the three cases in the non-elderly group, two presented with pulmonary vessel injury, two presented with calcified lymph nodes adherent to the pulmonary vessels accompanied by difficulty in separation, and one presented with pulmonary vessel injury.

Concerning long-time outcomes, during the last follow-up, a total of eighteen patients died in the elderly group, while a total of twenty-five patients died in the nonelderly group. There was no remarkable difference concerning mortality between both groups (Table 4). The five-year overall survival rates for the elderly and the nonelderly groups, were $67 \%$ and $71 \%$, respectively. There were, however, no significant statistical differences between both groups (Fig. 1, P = 0.358). Univariate analysis showed that the $T$ stage, SCS, N stage, and the ASA score significantly affected the five-year OS rate (Table 5). Age, gender, histological type, pathological type, and tumor laterality do not affect the five-year OS rate (Table 5). MCR analysis showed that SCS $\geq 9$, T3-T4 stage, and N2 stage were independent risk factors affecting the five-year OS rate (Table 6).

Table 4 Comparison of follow-up data of the two groups

\begin{tabular}{cccc}
\hline Outcomes & $\begin{array}{c}\text { Elderly } \\
(n=77)\end{array}$ & Nonelderly $(n=141)$ & $P$ value \\
\hline Mortality & 18 & 25 & 0.151 \\
Death from primary cancer & 16 & 24 & \\
Death from other diseases & 2 & 1 & 0.361 \\
Overall recurrence & 20 & 29 & \\
Local recurrence & 6 & 8 & \\
Distant recurrence & 16 & 18 & \\
Concurrent recurrence & 2 & 3 & 0.495 \\
Time to first cancer recurrence (median, months) & $18(10-45)$ & $15(15-47)$ & \\
\hline
\end{tabular}

Table 5 Univariate Kaplan-Meier analysis of overall survival 


\begin{tabular}{lcc}
\hline \multicolumn{1}{c}{ Variable } & Five-year overall survival & $P$ value \\
\hline Age & 71 & 0.358 \\
<70 years & 67 & \\
$\geq 70$ years & 70 & 0.287 \\
Gender & 65 & \\
Male & & 0.037 \\
Female & 62 & \\
SCS & 74 & 0.079 \\
$\quad \geq 9$ & & \\
$<9$ & 73 & \\
ASA score & 66 & 0.028 \\
I-II & & \\
III & & 0.034 \\
& 78 & \\
T stage & 63 & 0.574 \\
T1-T2 & & \\
T3-T4 & 75 & \\
N stage & 66 & \\
N0-N1 & & \\
N2 & & \\
Histological type & 63 & \\
Adenocarcinoma & & \\
Squamous cell carcinoma & & \\
Tumor laterality & 73 & \\
Left & 67 & \\
Right & & \\
& &
\end{tabular}

SCS: Simplified Comorbidity Score

ASA: American Society of Anesthesiologists

Table 6 Cox proportional hazards model for overall survival

\begin{tabular}{lcc}
\hline \multicolumn{1}{c}{ Variables } & Hazard ratio $(95 \% \mathrm{CI})$ & $P$ value \\
\hline SCS $<9$ versus $\geq 9$ & $1.528(1.215-1.922)$ & 0.044 \\
T stage T1-T2 versus T3-T4 & $2.358(1.478-3.762)$ & 0.032 \\
N stage N0-N1 versus N2 & $2.684(1.589-4.534)$ & 0.019 \\
ASA score I-II versus III & $1.347(0.678-2.676)$ & 0.120 \\
\hline
\end{tabular}

SCS: Simplified Comorbidity Score

ASA: American Society of Anesthesiologists

The five-year disease-free rates for the elderly and the nonelderly were $59 \%$ and $66 \%$, respectively. There were, however, no significant statistical differences between both groups (Fig. 2, $\mathrm{P}=0.289$ ). Univariate analysis showed that SCS, T stage, and N stage affected 5-year disease-free rate (Table 7). Age, gender, histological type, ASA score, pathological type, and tumor laterality have no effect on 5-year disease-free rate (Table 7). Multivariate analysis showed that SCS $\geq 9$, T3-T4 stage, and N2 stage were independent risk factors that affected the 5-year disease-free rate (Table 8).

Table 7 Univariate Kaplan-Meier analysis of disease-free survival 


\begin{tabular}{lcc}
\hline \multicolumn{1}{c}{ Variable } & Five-year overall survival & $P$ value \\
\hline Age & 66 & 0.289 \\
$\quad<70$ years & 59 & \\
$\geq 70$ years & 67 & 0.207 \\
Gender & 58 & \\
Male & & 0.045 \\
Female & 54 & \\
SCS & 71 & 0.149 \\
$\quad \geq 9$ & & \\
$\quad<9$ & 65 & \\
ASA score & 58 & 0.030 \\
I-II & & \\
III & & 0.027 \\
& 71 & \\
T stage & 54 & 0.578 \\
T1-T2 & & \\
T3-T4 & 69 & \\
N stage & 53 & \\
N0-N1 & & \\
N2 & 67 & \\
Histological type & 61 & \\
Adenocarcinoma & & \\
Squamous cell carcinoma & 68 & \\
Tumor laterality & 62 & \\
Left & & \\
Right & & \\
& &
\end{tabular}

SCS: Simplified Comorbidity Score

ASA: American Society of Anesthesiologists

Table 8 Cox proportional hazards model for overall survival

\begin{tabular}{lcc}
\hline \multicolumn{1}{c}{ Variables } & Hazard ratio (95\% CI) & $P$ value \\
\hline SCS $<9$ versus $\geq 9$ & $1.594(1.114-2.281)$ & 0.031 \\
T stage T1-T2 versus T3-T4 & $1.974(1.257-3.099)$ & 0.040 \\
N stage N0-N1 versus N2 & $3.007(1.700-5.319)$ & 0.010 \\
\hline
\end{tabular}

SCS: Simplified Comorbidity Score

ASA: American Society of Anesthesiologists

\section{Discussion}

Older patients have a poor preoperative pulmonary function, and an increased risk of postoperative pulmonary complications. The risk of pulmonary complications in patients with FEV1 less than $2 \mathrm{~L}$ and less than $1 \mathrm{~L}$ is moderate and high, respectively. PF test criteria for lobectomy are a forced expiratory volume in 1 second (FEV1) $>1.0 \mathrm{~L}$ and maximum voluntary ventilation (MVV) $>40 \%$ of predicted [7-9]. In this study, the older patients had poor pulmonary function performance as compared to their counterparts, which indicated that the postoperative risk complications were higher with older patients $(\geq$ 70 years of age) as compared to younger patients ( $\leq 70$ years of age). The ERAS model was first proposed by the Danish surgeon Kehlet in 1997[39-41]. It refers to the comprehensive use of a series of optimization measures supported by evidence-based medicine during the perioperative period, including multidisciplinary collaboration of surgery, anesthesia, nursing, and nutrition, to optimize the clinical 
pathway for perioperative management, in order to reduce the perioperative stress response (i.e., physiological and psychological traumatic stress) and postoperative complications in surgical patients with the aim of achieving the best health status and rapid recovery with minimal cost. Since the ERAS model was successfully applied for the first time in gastrointestinal surgery, this concept has now been adopted in neurosurgery, thoracic surgery, and other surgical fields [39-41]. Studies have shown that under the ERAS protocol, it is possible to effectively reduce surgical trauma and postoperative stress response, shorten the length of hospitalization, and promote patient recovery in the perioperative period of VATS lobectomy[39-41]. The results of our study revealed that postoperative complications and severe complications in the elderly group were similar to that of the nonelderly group. This suggests that although the preoperative pulmonary function of elderly NSCLC patients is worse than the non-elderly patients, VATS lobectomy allows elderly NSCLC patients to have similar short-term outcomes as nonelderly patients, thus indicating the safety of VATS lobectomy for the treatment of elderly NSCLC patients.

Postoperative complications after VATS may adversely affect the long-term outcomes [7-9]. The surgery may cause a systemic inflammatory reaction, and the level of inflammatory factors and C-reactive protein will increase [7-9]. Postoperative complications, especially major complications, may exacerbated Inflammation and immunosuppression [7-9]. The perioperative stress response will inhibit the activity of natural killer cells, increase tumor burden, inhibit endogenous mediators, lead to the downregulation of effector lymphocytes and regulatory pathways, and put the body in a state that promotes tumor growth [7-9]. Stress and inflammation caused by major postoperative complications may cause the residual cancer cells to grow and proliferation, which will have an adverse effect on long-term prognosis [7-9]. In this study, the postoperative 30-day complication rate and the rate of serious complications were similar in both groups, which may also be one of the reasons for the similar prognosis of the two groups.

The results of a prospective study showed that the local recurrence rates of early stage NSCLC patients underwent lobectomy are significantly lower than sublobar resection, and the survival rate is significantly higher than sublobar resection. Therefore, the current standard surgical procedure for early stage NSCLC is still anatomical lobectomy. Sublobar resection is currently still in clinical research. Two prospective multicenter randomized controlled trials comparing early lung cancer lobectomy with sublobar resection have been completed, and there are reports of short-term outcomes. Differences in surgical complications or mortality are statistically significant and are currently waiting for long-term follow-up results.

Conversion to thoracotomy is an inevitable phenomenon during VATS lobectomy [47-53]. The overall conversion to thoracotomy rate of the 218 patients included in this study was $1.7 \%$, and the two age groups had similar conversion to thoracotomy rates. A study by Sawada showed that the most important cause of conversion to thoracotomy was the calcification of lymph nodes and their adhesion to pulmonary vessels with subsequent difficult separation [47]. This accounted for $60 \%$ of the conversion to thoracotomy rates in our study. In contrast, a study demonstrated that the most common cause of conversion to thoracotomy was vascular injury leading to uncontrollable bleeding, and vascular injury is a common cause of conversion to thoracotomy in minimally invasive surgery such as thoracoscopic esophagectomy and laparoscopic gastrectomy [48]. Although conversion to thoracotomy can cause 
prolonged operation duration, increased length of postoperative hospital stay, and increased postoperative pain, it does not cause serious complications or death.

It is common for elderly NSCLC patients to have comorbidities, and the impact of comorbidities on elderly NSCLC patients is getting more and more attention. Charlson Comorbidity Index (CCl) and SCS are the two commonly used methods to assess comorbidities. Compared with $\mathrm{CCI}, \mathrm{SCS}$ can more accurately assess the impact of comorbidities on the prognosis of NSCLC patients. Through a prospective study of 136 elderly NSCLC patients, Colinet et al. showed that the median survival of patients with a score of $\leq 9$ was longer than those with a score of $>9$, suggesting that a SCS of $>9$ is an unfavorable prognostic factor in elderly NSCLC patients [54], which is consistent with the results of this study. In the SCS scheme, smoking accounts for a high proportion (weighting $=7$ ) of the total score, as smoking has been confirmed to be closely related to the incidence of common comorbidities in elderly patients such as cardiovascular and respiratory diseases. Therefore, the SCS method provides a more objective and comprehensive assessment of comorbidities in NSCLC patients and is more suitable for studying the impact of comorbidities on the prognosis of NSCLC patients.

VATS lobectomy is mainly performed through multiple incisions, predominantly three incisions, and the three-incision method was also adopted in this study. Minimally invasive surgery is one of the growing developments of surgery. At present, single-incision endoscopic surgeries such as single-incision appendectomy and single-incision cholecystectomy are widely performed [55, 56]. Since Gonzalez's first report of single-incision VATS lobectomy [57], retrospective studies have shown that single-incision VATS lobectomy is safe and feasible [58-62]. In 2016, a randomized controlled trial comparing single-incision versus multi-incision VATS lobectomy revealed that the two groups of patients demonstrated similarities in short-term outcomes such as analgesic medication use, duration of chest tube placement, length of postoperative hospital stay, and incidence of complications [63]. However, there are few reports on longterm outcomes of single-incision VATS lobectomy in the treatment of NSCLC. The key to evaluating a new minimally invasive tumor surgery is the long-term survival rate. Consequently, we should refrain from performing single-incision VATS lobectomy untill sufficient research progress has been made.

The present study suffered from numerous limitations since the study was a single-center retrospective analysis with limited sample size; thus, the possibility of selection bias is inevitable.

\section{Conclusion}

This study shows that NSCLC treatment with VATS lobectomy is safe and feasible in elderly patients, and it can provide good long-term outcomes. However, it is necessary to strengthen perioperative management and promote early postoperative recovery so as to reduce complications.

\section{Abbreviations}

VATS: video-assisted thoracoscopic 
NSCLC: non-small-cell lung cancer

SCS: simplified comorbidity score

ASA: American Society of Anesthesiologists

ERAS: Enhanced Recovery After Surgery

CCl: Charlson Comorbidity Index

\section{Declarations}

\section{Acknowledgements}

We sincerely thank our hospital colleagues who participated in this research.

\section{Funding}

None

\section{Author information}

Affiliations

${ }^{1}$ Department of Thoracic Surgery, Yanan University Affiliated Hospital, Yan'an, No. 43 Beida Street, Yan'an, Shaanxi 716000, People's Republic of China

Yang Yang ${ }^{1}$, Kai Wang ${ }^{1}$, Qingquan Ren ${ }^{1}$, Ruibin $\mathrm{Xu}^{1}$, Jianfeng Guo ${ }^{1}$

\section{Contributions}

YY and JG contributed to study conception and design, QiR, RX and JG contributed to acquisition of data, $\mathrm{Q} R, \mathrm{RX}$ and JG contributed to analysis and interpretation of data, $Y Y$ and JG contributed to drafting of manuscript, YY and JG contributed to critical revision.

\section{Corresponding author}

Correspondence to Jianfeng Guo

\section{Ethics declarations}

Ethics approval and consent to participate

The study was approved by ethics review board of Yanan University Affiliated Hospital. Due to the retrospective study design and the anonymization of data, consent to participate was not necessary. 


\section{Consent for publication}

All the authors agreed to the publication of this work.

\section{Competing interests}

No competing interest by the authors.

\section{References}

1. Miller KD, Nogueira L, Mariotto AB, et al. Cancer treatment and survivorship statistics, 2019. CA Cancer J Clin 2019; 69:363-385.

2. Siegel RL, Miller KD, Jemal A. Cancer statistics, 2020. CA Cancer J Clin 2020; 70:7-30.

3. Nasim F, Sabath BF, Eapen GA. Lung Cancer. Med Clin North Am 2019; 103:463-473.

4. Herbst RS, Morgensztern D, Boshoff $C$. The biology and management of non-small cell lung cancer. Nature 2018; 553:446-454.

5. Decoster $L$, Schallier $D$. Treatment of older patients with advanced non-small cell lung cancer: $A$ challenge. J Geriatr Oncol 2019; 1:528-533.

6. Quoix E. Optimal pharmacotherapeutic strategies for elderly patients with advanced non-small cell lung cancer. Drugs Aging 2011; 28:885-894.

7. Gajra A, Akbar SA, Din NU. Management of Lung Cancer in the Elderly. Clin Geriatr Med 2016;32:8195.

8. Duma N, Santana-Davila R, Molina JR. Non-Small Cell Lung Cancer: Epidemiology, Screening, Diagnosis, and Treatment. Mayo Clin Proc 2019; 94:1623-1640.

9. Rocco G, Weder W. Lung surgery in the elderly today. Lung Cancer 2013; 80:115-119.

10. Leduc C, Antoni D, Charloux A, Falcoz PE, Quoix E. Comorbidities in the management of patients with lung cancer. Eur Respir J 2017; 49:1601721.

11. Roviaro G, Rebuffat C, Varoli F, Vergani C, Mariani C, Maciocco M. Videoendoscopic pulmonary lobectomy for cancer. Surg Laparosc Endosc 1992; 2:244-247.

12. Yang $X$, Wang $S$, Qu J. Video-assisted thoracic surgery (VATS) compares favorably with thoracotomy for the treatment of lung cancer: a five-year outcome comparison. World J Surg 2009; 33:1857-1861.

13. Ghaly G, Kamel M, Nasar A, Paul S, Lee PC, Port JL, Stiles BM, Altorki NK. Video-Assisted Thoracoscopic Surgery Is a Safe and Effective Alternative to Thoracotomy for Anatomical Segmentectomy in Patients With Clinical Stage I Non-Small Cell Lung Cancer. Ann Thorac Surg 2016; 101:465-472; discussion 472.

14. Kim K, Kim HK, Park JS, Chang SW, Choi YS, Kim J, Shim YM. Video-assisted thoracic surgery lobectomy: single institutional experience with 704 cases. Ann Thorac Surg 2010; 89:S2118-S2122.

15. Oda R, Okuda K, Osaga S, Watanabe T, Sakane T, Tatematsu T, Yokota K, Haneda H, Nakanishi R. Long-term outcomes of video-assisted thoracoscopic surgery lobectomy vs. thoracotomy lobectomy 
for stage IA non-small cell lung cancer. Surg Today 2019; 49:369-377.

16. Zhao Y, Li G, Zhang Y, Hu H, Zhang J, Sun Y, Chen H. Comparison of outcomes between musclesparing thoracotomy and video-assisted thoracic surgery in patients with cT1 N0 M0 lung cancer. $J$ Thorac Cardiovasc Surg 2017; 154:1420-1429.e1.

17. Wang BY, Huang JY, Lin CH, Ko JL, Chou CT, Wu YC, Lin SH, Liaw YP. Thoracoscopic Lobectomy Produces Long-Term Survival Similar to That with Open Lobectomy in Cases of Non-Small Cell Lung Carcinoma: A Propensity-Matched Analysis Using a Population-Based Cancer Registry. J Thorac Oncol 2016; 11:1326-1334.

18. Nakano T, Endo S, Endo T, Otani S, Tsubochi H, Yamamoto S, Tetsuka K. Surgical Outcome of VideoAssisted Thoracoscopic Surgery vs. Thoracotomy for Primary Lung Cancer $>5 \mathrm{~cm}$ in Diameter. Ann Thorac Cardiovasc Surg 2015;21:428-34.

19. Shao W, Liu J, Liang W, Chen H, Li S, Yin W, Zhang X, He J. Safety and feasibility of video-assisted thoracoscopic surgery for stage IIIA lung cancer. Chin J Cancer Res 2014; 26:418-422.

20. Iwata H, Shirahashi K, Yamamoto H, Marui T, Matsumoto S, Mizuno Y, Matsumoto M, Mitta S, Miyamoto $\mathrm{Y}$, Komuro $\mathrm{H}$. Propensity score-matching analysis of hybrid video-assisted thoracoscopic surgery and thoracoscopic lobectomy for clinical stage I lung cancert. Eur J Cardiothorac Surg 2016; 49:1063-1067.

21. Lutz JA, Seguin-Givelet A, Grigoroiu M, Brian E, Girard P, Gossot D. Oncological results of full thoracoscopic major pulmonary resections for clinical Stage I non-small-cell lung cancer. Eur $\mathrm{J}$ Cardiothorac Surg 2019; 55:263-270.

22. Shao W, Xiong X, Chen H, Liu J, Yin W, Li S, Xu X, Zhang X, He J. Long-term survival outcomes of video-assisted thoracic surgery for patients with non-small cell lung cancer. Chin J Cancer Res 2014; 26:391-398.

23. Yang HX, Woo KM, Sima CS, Bains MS, Adusumilli PS, Huang J, Finley DJ, Rizk NP, Rusch VW, Jones DR, Park BJ. Long-term Survival Based on the Surgical Approach to Lobectomy For Clinical Stage I Nonsmall Cell Lung Cancer: Comparison of Robotic, Video-assisted Thoracic Surgery, and Thoracotomy Lobectomy. Ann Surg 2017; 265:431-437.

24. Mei J, Guo C, Xia L, Liao H, Pu Q, Ma L, Liu C, Zhu Y, Lin F, Yang Z, Zhao K, Che G, Liu L. Long-term survival outcomes of video-assisted thoracic surgery lobectomy for stage I-II non-small cell lung cancer are more favorable than thoracotomy: a propensity score-matched analysis from a highvolume center in China. Transl Lung Cancer Res 2019; 8:155-166.

25. Bu L, Li Y, Yang F, Zhao H, Jiang GC, Li JF, Liu J, Wang J. Completely video-assisted thoracoscopic lobectomy versus open lobectomy for non-small cell lung cancer greater than $5 \mathrm{~cm}$ : a retrospective study. Chin Med J (Engl) 2012; 125:434-439.

26. Haruki T, Miwa K, Araki K, Taniguchi Y, Nakamura H. Distribution and Prevalence of Locoregional Recurrence after Video-Assisted Thoracoscopic Surgery for Primary Lung Cancer. Thorac Cardiovasc Surg 2016;64:526-532. 
27. Hanna WC, de Valence M, Atenafu EG, Cypel M, Waddell TK, Yasufuku K, Pierre A, De Perrot M, Keshavjee S, Darling GE. Is video-assisted lobectomy for non-small-cell lung cancer oncologically equivalent to open lobectomy? Eur J Cardiothorac Surg 2013; 43:1121-1125.

28. Ettinger DS, Wood DE, Aggarwal C, Aisner DL, Akerley W, Bauman JR, Bharat A, Bruno DS, Chang JY, Chirieac LR, D'Amico TA, Dilling TJ, Dobelbower M, Gettinger S, Govindan R, Gubens MA, Hennon M, Horn L, Lackner RP, Lanuti M, Leal TA, Lin J, Loo BW Jr, Martins RG, Otterson GA, Patel SP, Reckamp KL, Riely GJ, Schild SE, Shapiro TA, Stevenson J, Swanson SJ, Tauer KW, Yang SC, Gregory K; OCN, Hughes M. NCCN Guidelines Insights: Non-Small Cell Lung Cancer, Version 1.2020. J Natl Compr Canc Netw 2019; 17:1464-1472.

29. Cattaneo SM, Park BJ, Wilton AS, Seshan VE, Bains MS, Downey RJ, Flores RM, Rizk N, Rusch VW. Use of video-assisted thoracic surgery for lobectomy in the elderly results in fewer complications. Ann Thorac Surg 2008; 85:231-235; discussion 235-6.

30. Koizumi K, Haraguchi S, Hirata T, Hirai K, Mikami I, Fukushima M, Okada D, Yamagishi S, Enomoto Y, Nakayama K, Akiyama H, Tanaka S. Lobectomy by video-assisted thoracic surgery for lung cancer patients aged 80 years or more. Ann Thorac Cardiovasc Surg 2003; 9:14-21.

31. Amer K, Khan AZ, Vohra H, Saad R. Is it safe to include octogenarians at the start of a video-assisted thoracic surgery lobectomy programme? Eur J Cardiothorac Surg 2012; 41:346-52.

32. Koizumi K, Haraguchi S, Hirata T, Hirai K, Mikami I, Fukushima M, Kubokura H, Okada D, Akiyama H, Tanaka S. Video-assisted lobectomy in elderly lung cancer patients. Jpn J Thorac Cardiovasc Surg 2002; 50:15-22.

33. Xue Y, Wang YY, Zhang K, Cong W, He B, Zeng FC. A Study of Complete Video-Assisted Thoracoscopic Surgery Lobectomy in Treatment of Elderly Patients with Non-Small Cell Lung Cancer: Curative Effect and Impact on Clinical Prognosis. Cell Biochem Biophys 2015; 73:399-404.

34. Port JL, Mirza FM, Lee PC, Paul S, Stiles BM, Altorki NK. Lobectomy in octogenarians with non-small cell lung cancer: ramifications of increasing life expectancy and the benefits of minimally invasive surgery. Ann Thorac Surg 2011; 92:1951-1957.

35. Sui X, Zhao H, Wang J, Yang F, Yang F, Li Y. Outcome of VATS Lobectomy for Elderly Non-Small Cell Lung Cancer: A Propensity Score-Matched Study. Ann Thorac Cardiovasc Surg 2015; 21:529-535.

36. Fong LS, Ko V, Mclaughlin A, Okiwelu NL, Newman MA, Passage J, Sanders LHA, Joshi PV. Outcomes of video-assisted thoracoscopic surgery lobectomy in septuagenarians. ANZ J Surg 2020; 90:752756.

37. Zhang L. Short- and long-term outcomes in elderly patients with locally advanced non-small-cell lung cancer treated using video-assisted thoracic surgery lobectomy. Ther Clin Risk Manag 2018; 14:22132220.

38. Long H, Tan Q, Luo Q, Wang Z, Jiang G, Situ D, Lin Y, Su X, Liu Q, Rong T. Thoracoscopic Surgery Versus Thoracotomy for Lung Cancer: Short-Term Outcomes of a Randomized Trial. Ann Thorac Surg 2018; 105:386-392. 
39. Brunelli A, Thomas C, Dinesh P, Lumb A. Enhanced recovery pathway versus standard care in patients undergoing video-assisted thoracoscopic lobectomy. J Thorac Cardiovasc Surg 2017; 154:2084-2090.

40. Gonzalez M, Abdelnour-Berchtold E, Perentes JY, Doucet V, Zellweger M, Marcucci C, Ris HB, Krueger T, Gronchi F. An enhanced recovery after surgery program for video-assisted thoracoscopic surgery anatomical lung resections is cost-effective. J Thorac Dis 2018; 10:5879-5888.

41. Dinic VD, Stojanovic MD, Markovic D, Cvetanovic V, Vukovic AZ, Jankovic RJ. Enhanced Recovery in Thoracic Surgery: A Review. Front Med (Lausanne) 2018; 5:14.

42. Clavien PA, Barkun J, de Oliveira ML, Vauthey JN, Dindo D, Schulick RD, de Santibañes E, Pekolj J, Slankamenac K, Bassi C, Graf R, Vonlanthen R, Padbury R, Cameron JL, Makuuchi M. The ClavienDindo classification of surgical complications: five-year experience. Ann Surg 2009; 250:187-96.

43. Lv J, Song R, Cai H, Lu C. Outcomes of laparoscopic radical nephrectomy for elderly patients with localized renal cell carcinoma. J BUON 2019; 24:2147-2154.

44. Abu Arab W. Video-assisted thoracoscopic surgery for non-small cell lung cancer. Minim Invasive Surg Oncol 2017; 1: 1-11.

45. Liu Z, Yang R, Shao F. Anastomosis using complete continuous suture in uniportal video-assisted thoracoscopic bronchial sleeve lobectomy. Minim Invasive Surg Oncol 2017; 1: 31-42.

46. Fang W, Ruan W. Advances in uniportal video-assisted thoracoscopic surgery for non-small cell lung cancer. Minim Invasive Surg Oncol 2017; 1: 20-30.

47. Sawada S, Komori E, Yamashita M. Evaluation of video-assisted thoracoscopic surgery lobectomy requiring emergency conversion to thoracotomy. Eur J Cardiothorac Surg 2009; 36:487-90.

48. Starnes SL. Analyzing intraoperative conversion of thoracoscopic lobectomy: acceptable outcome or failure? J Thorac Dis 2019; 11:643-645.

49. Matsuoka K, Yamada T, Matsuoka T, Nagai S, Ueda M, Miyamoto Y. Analysis of conversion to thoracotomy during thoracoscopic lung resection. Asian Cardiovasc Thorac Ann 2019; 27:381-387.

50. Mun M, Nakao M, Matsuura Y, Ichinose J, Nakagawa K, Okumura S. Video-assisted thoracoscopic surgery lobectomy for non-small cell lung cancer. Gen Thorac Cardiovasc Surg 2018; 66:626-631.

51. Liu K, Zhao J, Zhang W, Tan J, Ma J, Pei Y. Video-assisted thoracoscopic surgery for non-small-cell lung cancer in elderly patients: a single-center, case-matched study. Int J Clin Exp Med 2015; 8:11738-11745.

52. Wang Y. Video-assisted thoracoscopic surgery for non-small-cell lung cancer is beneficial to elderly patients. Int J Clin Exp Med 2015; 8:13604-13609.

53. Ball D, Thursfield V, Irving L, Mitchell P, Richardson G, Torn-Broers Y, Wright G, Giles G. Evaluation of the Simplified Comorbidity Score (Colinet) as a prognostic indicator for patients with lung cancer: a cancer registry study. Lung Cancer 2013; 82:358-561.

54. Colinet B, Jacot W, Bertrand D, Lacombe S, Bozonnat MC, Daurès JP, Pujol JL; oncoLR health network. A new simplified comorbidity score as a prognostic factor in non-small-cell lung cancer 
patients: description and comparison with the Charlson's index. Br J Cancer 2005; 93:1098-1105.

55. Castellanos A, Fazendin J, Panait L. Single-incision laparoscopic cholecystectomy. Clin Liver Dis (Hoboken) 2015; 5:5-7.

56. Raakow J, Liesaus HG, Neuhaus P, Raakow R. Single-incision versus multiport laparoscopic appendectomy: a case-matched comparative analysis. Surg Endosc 2015; 29:1530-1536.

57. Gonzalez D, Paradela M, Garcia J, Dela Torre M. Single-port video-assisted thoracoscopic lobectomy. Interact Cardiovasc Thorac Surg 2011; 12:514-515.

58. Wu Z, Wang Q, Wu C, Zhan T, Dong L, Fang S, Peng X, Wang L, Pan S, Wu M. Three-port singleintercostal versus multiple-intercostal thoracoscopic lobectomy for the treatment of lung cancer: a propensity-matched analysis. BMC Cancer 2019; 19:8.

59. Wang L, Liu D, Lu J, Zhang S, Yang X. The feasibility and advantage of uniportal video-assisted thoracoscopic surgery (VATS) in pulmonary lobectomy. BMC Cancer 2017; 17:75.

60. Xie D, Wang H, Fei K, Chen C, Zhao D, Zhou X, Xie B, Jiang L, Chen Q, Song N, Dai J, Jiang G, Zhu Y. Single-port video-assisted thoracic surgery in 1063 cases: a single-institution experience. Eur $\mathrm{J}$ Cardiothorac Surg 2016; i31-i36.

61. Yang X, Wang L, Zhang C, Zhao D, Lu Y, Wang Z. The Feasibility and Advantages of Subxiphoid Uniportal Video-Assisted Thoracoscopic Surgery in Pulmonary Lobectomy. World J Surg 2019; 43:1841-1849.

62. Al-Ameri M, Sachs E, Sartipy U, Jackson V. Uniportal versus multiportal video-assisted thoracic surgery for lung cancer. J Thorac Dis 2019; 11:5152-5161.

63. Perna V, Carvajal AF, Torrecilla JA, Gigirey O. Uniportal video-assisted thoracoscopic lobectomy versus other video-assisted thoracoscopic lobectomy techniques: a randomized study. Eur $\mathrm{J}$ Cardiothorac Surg 2016; 50:411-415.

\section{Figures}




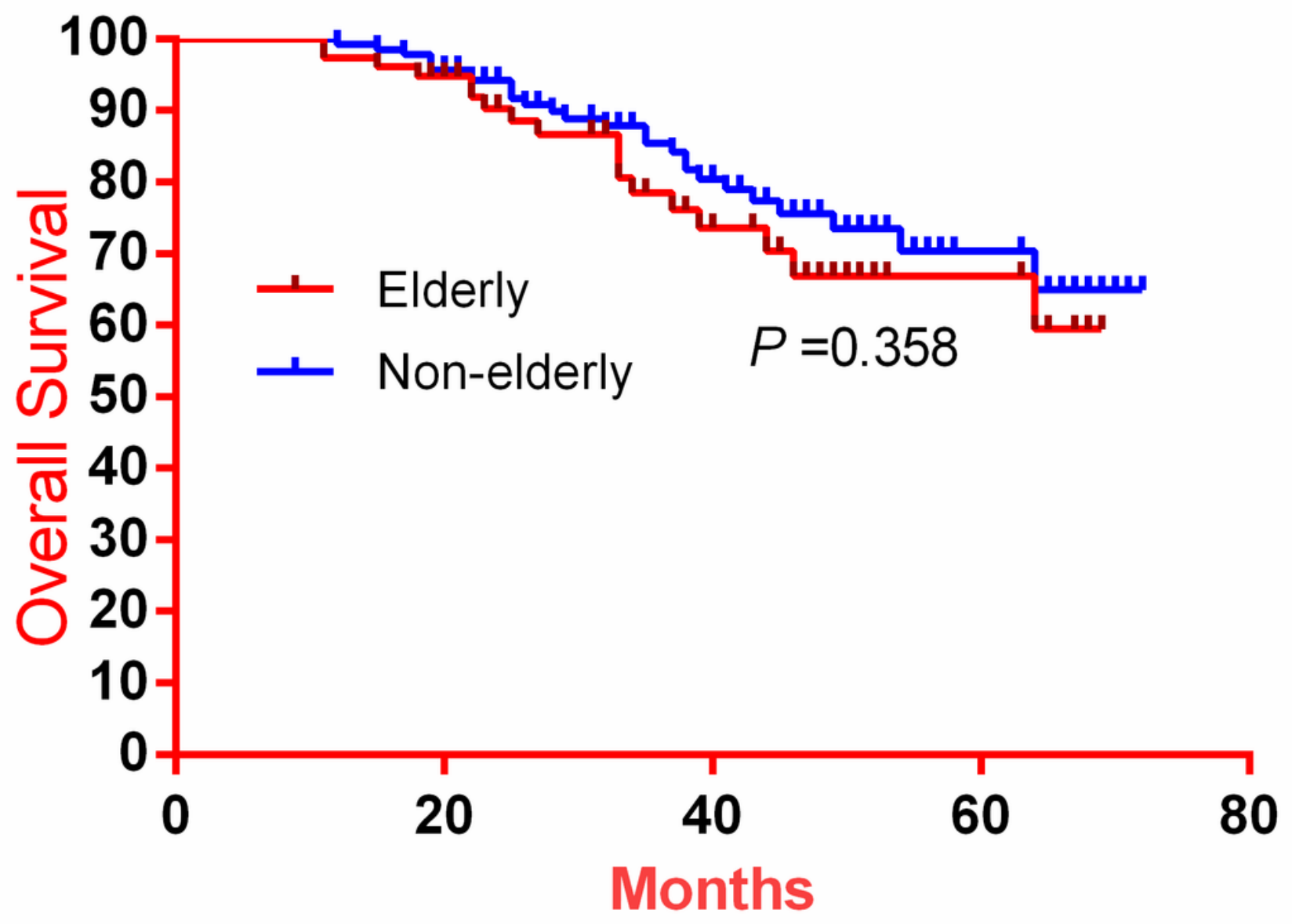

Figure 1

Comparison of overall survival rates after VATS lobectomy for NSCLC between elderly and middle-aged patients $(P=0.358)$. 


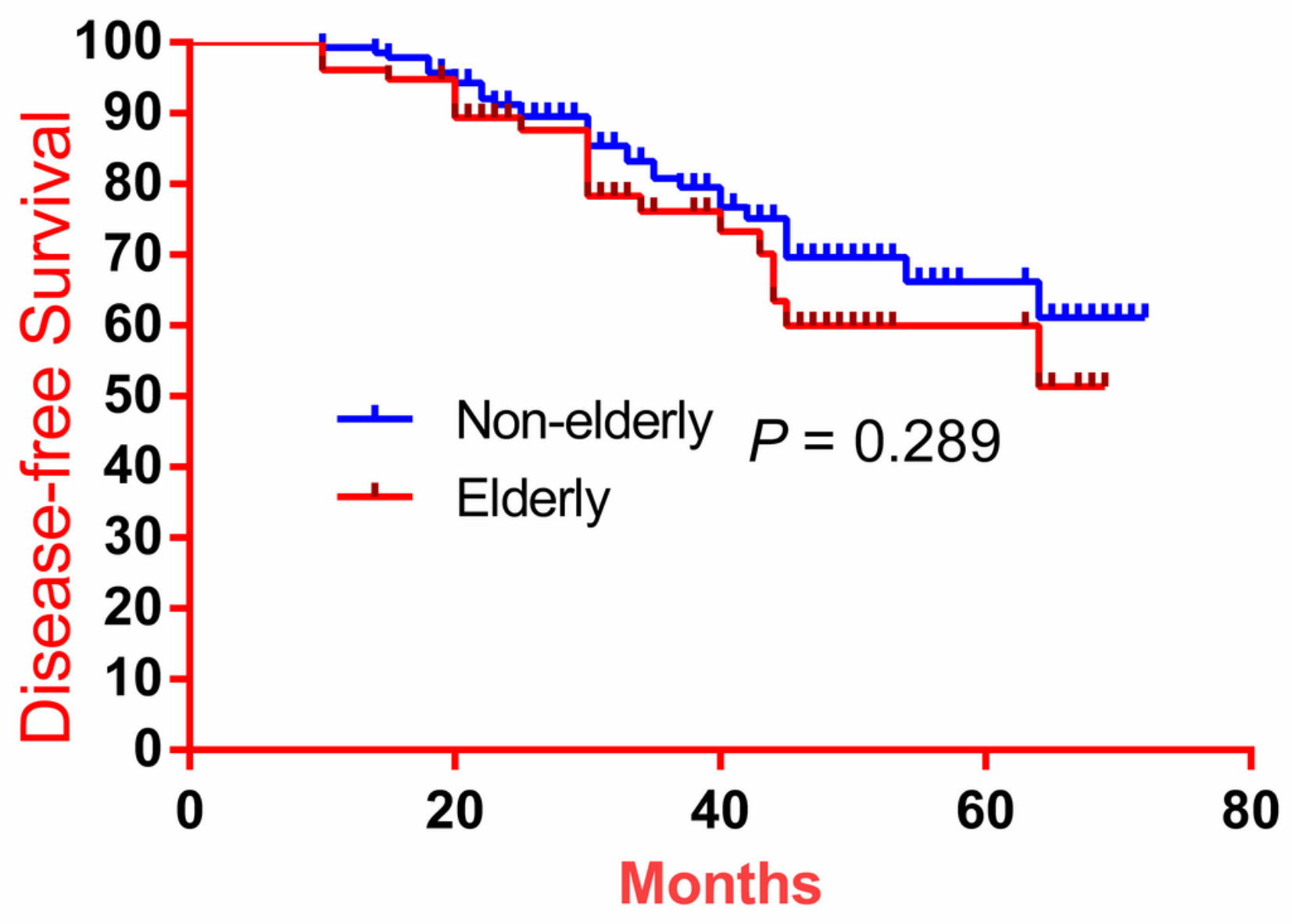

Figure 2

Comparison of disease-free survival rates after VATS lobectomy for NSCLC between elderly and middleaged patients $(P=0.289)$. 